\title{
Browsing the Web for Shoosing a Touristic Destination
}

\author{
Dhouka Oueldoubey Habibeche, Imed Zaiem \\ ERMA Laboratory, Fsegt, Tunis El Manar, Tunis, Tunisia \\ Email: Oueldoubey.dhouka@yahoo.fr
}

Received 26 March 2014; revised 28 April 2014; accepted 25 May 2014

Copyright (C) 2014 by authors and Scientific Research Publishing Inc.

This work is licensed under the Creative Commons Attribution International License (CC BY). http://creativecommons.org/licenses/by/4.0/

c) (i) Open Access

\begin{abstract}
Nowadays, a new solution for choosing a tourism destination is to use Internet. In fact, this media gives us an opportunity to discover an unlimited number of offers due to the characteristics of website atmosphere. That's why this paper aims to conceptualize a particular behavior on the net: E-Browsing.
\end{abstract}

Keywords

E-Browsing, Web Site Atmosphere, Choice of Touristic Web Site

\section{Introduction}

Browsing websites, the future tourist is faced to a variety of offers where he can compare, see reviews and even customize some services. In this regard, this behavior is strongly influenced by a number of variables that will promote development and encourage the user to extend his visit. Some variables are related to the web site atmosphere, the other ones are personal variables.

\section{Browsing Behaviour}

\subsection{In Real Store}

According to Bloch and Rechins [1], and Lombart [2], browsing can be defined as a hobby activity in stores, realized without a specific purchasing intention, the motivations of which are principally reactivated. Therefore, it turns out that the browser is an individual who happens to be in the store without a specific purchasing objective. In fact, this behavior has existed since the first forms of outlet stores in various fields; however, it is now more noticeable due to the emergence of the constitutive variables of a store. According to Filser (2003), the atmosphere of a store incites the consumer's interest and invites the latter to be present in that universe only to discover which 
drives him/her to extend visiting time, which on its turns explains the browsing behavior within that space.

From another angle, Lombart and Labbé-Pinlon [3] consider browsing similar to "just looking” or "taking a tour". In addition, Bloch and Richins [1] define the act of browsing as being "the examination of products in a store for a recreational or an informational purpose, with no purchasing intention”.

In fact, Lombart [3] informs us that these consumers are present in practically all the signboard types (such as tableware, cosmetics, bookstores and/or clothing). They go by the sellers and the actual buyers motivated only by their desire to meet people, entertain themselves and have fun. Furthermore, this client category is largely influenced by the stores' setting. Thereby, Lombart and Labbé-Pinlon [2] find that certain decorating variables are considered as "hooks" for these browsers justifying their behavior and presence in a store. Thus, Filser (2003) considers that the buyer is confronted to several elements that appeal to emotions and symbolic evocations.

Manipulation of environmental variables brings us to think for long the word "atmosphere" meant purely real concept. Among the first research we include the classification of Baker (1986) which divides the atmospheric variables of a website into three categories:

- The atmosphere factors: smell, music, color...

- The design factors: storage of items, store organization and its structure.

- Social factors: customer relationship seller inside the store.

Also, according to Lemoine [4], only the store variables compose its atmosphere. In fact, these variables, their arrangements act fully on the consumer behavior, its emotional and therefore the decision to purchase.

This is called "the atmosphere stores". The advantage of such stores to the consumer is that to allow him to live special experience through Physical elements adding a special atmosphere to the place. Competition in this respect seems increased and the causes are varied. Bonnefont (2002) informs us about the main motivations for creating pleasant and conducive to visit places.

\subsection{In Virtual Stores}

According to Danaher et al. [5], the website is assimilated to a virtual store in which sellers and buyers exchange relationships. Research on the impact of the atmosphere of a website on the surfer's behavior present a large exploitation field. Indeed, several studies were focused on emotional and behavioral responses of the consumer in a website but not on the latter's browsing behavior. At this stage, our study seems interesting in the sense that it will provide the advantages that explain online browsing behavior.

As we are oriented towards the digital world, it is convenient to propose a definition of the online browsing behavior that actually consists in surfing a website without the intention to make an electronic purchase. It is rather for distraction, discovery and data collection purposes. This visit is oriented by the atmospheric variables of the site that trigger the surfers' interest and drive them to spend more time navigating. The table below (Table 1) shows a number of services offered by a virtual store. It includes assortment, logistics, advices...

Table 1. Elements of the service package offered by a commercial site.

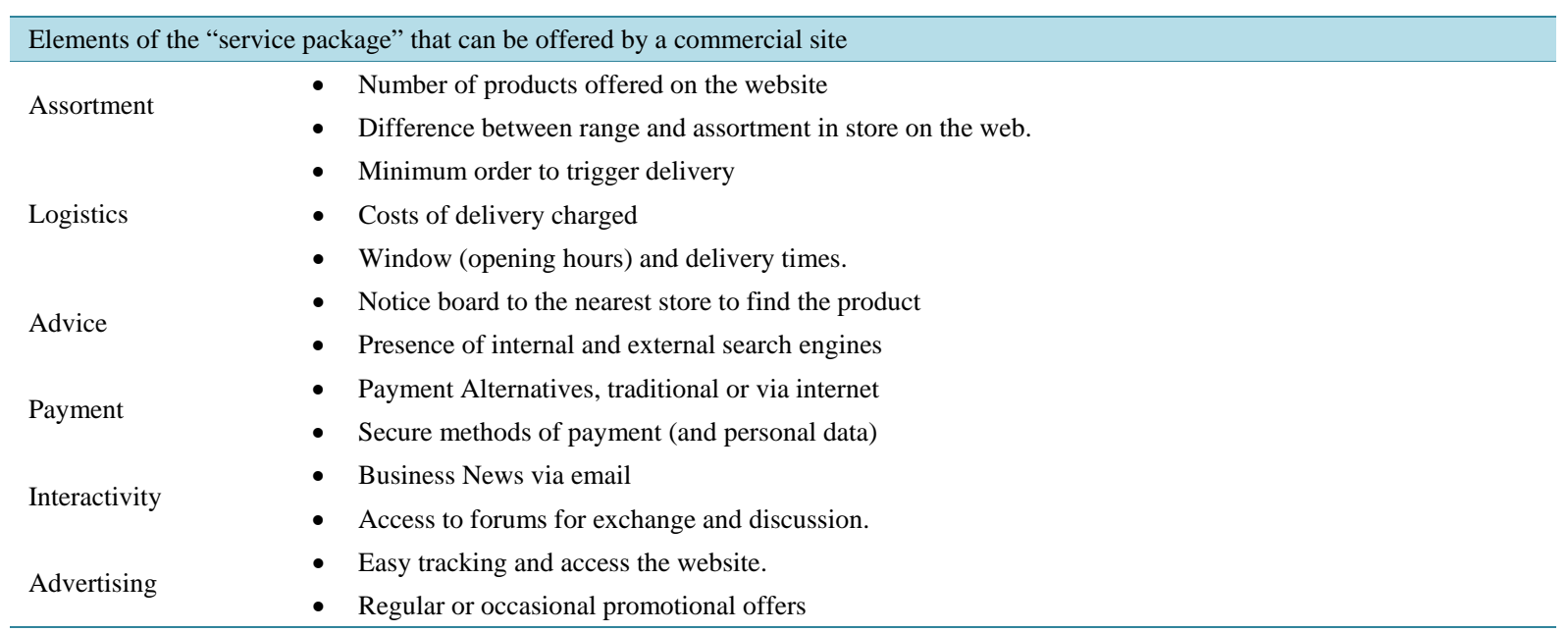

Source: Kotzab et Madelberger (2001). 


\section{Relationship between Tourism and Internet}

The World Tourism Office defines tourism with reference to its functional and organic features linking development, production, distribution and marketing of products and services designed to meet the travel needs and pleasures, an initiative that can come out of either private bodies, or public ones. According to Universalis encyclopedia, tourism is about spending leisure time outside one's principal residence place, having allocated an extra budget to cover expenses for that specific time. For Tissot (2007), the traveler uses the touristic fund to satisfy leisure needs and to take the maximum advantage of the touristic experience. The principal variables of tourism are transport, accommodation and attraction. Tourism is characterized by its limited duration, intangibility, the multiplicity of its components and by a well determined geographical area. Internet has taken the toll on tourism as a business; and, according to Hudson [6], many classic touristic companies make their own websites; whereas, others prefer referencing via other companies. Hence, the most active businesses of this sector, like airline companies, car rental agencies and international hotel chains, rapidly adhered to this strategy, cancelling all intermediaries and favorizing direct contact with the customer. In this context, statistics of online transactions have shown that most online purchasing is related to travel and transportation services, according to Hudson [6]. Internet and new information technologies were able to reflect their benefits on the sector of tourism by offering the ability to answer massive growing demands of the sector by maximizing the capacity, flexibility and connectivity. E-tourism is, thus, a sort of conquest to this new network. Internet provides benefits for all its users in the tourism business.

In fact, using this technology, in the hope of making a successful destination choice, is credited to the fact that Internet has no constraints of distance, time and place, and that it allows easy exchange of information, according to Russel, W. [7]. The first motive behind a tourist's choice of a short holiday, according to Pikes [8], is the need to relax, to re-energize, to take a step back from one's busy life, and to build new relations and live, for a while, by their standards.

The elements of a "service package", offered by a retail website, are multiple and linked to logistics and selected services (as per the chart below). Thus, according to the specialists, the distinction between websites is done, essentially, on the basis of whether or not the website provides an online retail service.

\subsection{Readability}

Readability is one of the main characteristics of a website. By this, we mean the ability of the internaut to understand the content of a website and satisfy his/her need with the minimum numbers of clicks possible.

According to Gonzalez [9], readability is the degree of ease with which the website guides the consumer and helps him eventually through his/her search. The same source cited above states that the perceived readability springs actually from the consumer's ability to explore the content of the website and to finally take decisions (know where he/she is, know where to go next, and know how to) (Lynch, 1974; O’Neill, 1991). But the perceived readability springs also from the customer's ease in making decisions (knowing how to look for the desired information, knowing how to go back to the starting point).

\subsection{Design}

Considered as the second variable of a website atmosphere retained by our research, it is defined as being the variable that guides the consumer through the website. We here speak of elements that provide comfort. These variables are also sub-divided into underlying variables which gives us the design that aims at facilitating the search.

According to Katerattenakul (2002), the design of a website relies essentially on the fact that it should facilitate the transaction, the pleasure or the search for information. We can then understand that the characteristics of a website take many aspects and dimensions: cognitive, social, ludic and technical. Each dimension is sub-developed in order to further add characteristics to a website such as the informational feature, popularity, entertainment, vivacity, interactivity and of course easy navigation.

We propose by the way this model that explains the relation between e-browsing behavior and web site atmosphere. This relation's verified due to the use of future tourists to internet to get more information about their next touristic destination. They navigate even to get pleasure and of course for information. That's exactly the definition of browsing since the ultimate hope's to discover. 


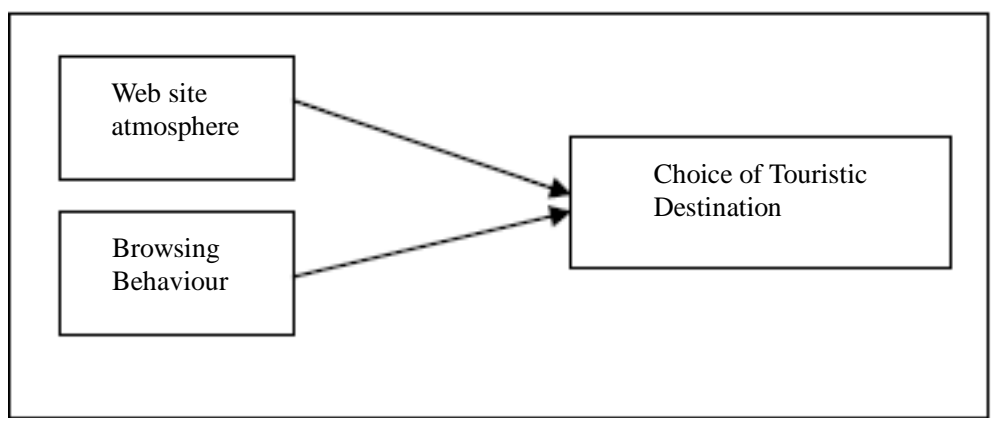

This research will enable the managers and decision makers either in health facilities or hotels to trace the line under behavior, to try to further satisfy them and study the constraints of attracting other groups of tourists as well. This will also help them improve their services and better target their customers, and will also help webmasters and people in charge of designing web sites to better focus their work on the previously studied affecting the internaut.

\section{Conclusion}

The interest of this work is to conceptualize a special behavior on line and its relationship for shoosing a touristic destination. Browsing is a behavior followed by internaute because of some antecedents such as time dispersibility or web site atmosphere. This person doesn't have the intention to act positively or finalize the purchase process. He's only there for discovery. That's why we find a relation between the choices of touristic destination and browsing the net, this work is to collect information and discover.

\section{References}

[1] Bloch, P.H. and Richins, M.L. (1983) Shopping without Purchase: An Investigation of Consumer Browsing Behavior. Advances in Consumer Research, 10, 389-393.

[2] Lombart, C. and Labbé-Pinlon, B. (2006) Identification des antécédents du comportement de butinage au sein de l’espace de loisir d'un hypermarché. Revue Française du Marketing, 17, 90-101.

[3] Lombart, C. and Labbé-pinlon, B. (2008) Comprendre et satisfaire les consommateurs qui butinent. Gestion, 23, $254-260$.

[4] Lemoine, J.F. (2005) L’atmosphère du point de vente comme variable stratégique commercial: Bilan et Perspectives. Décision Marketing, No. 39, 79-82.

[5] Danaher, J. (2006) Factors Affecting Web Site Visit Duration, a Cross-Domain Analysis. Journal of Marketing Research, 43, 182-194.

[6] Hudson, S. and Lang, N. (2002) A Destination Case Study of Marketing Tourism on Line: Bnaff, Canada. Journal of Vacation Marketing, 8, 155-165. http://dx.doi.org/10.1177/135676670200800205

[7] Russel, W. (2007) Online Accessibility and Information Needs of Disabled Tourists. Journal of Electronic Commerce Research, 8, 157-171.

[8] Pike, S. (2006) Destination Decision Sets: A Longitudinal Comparison of Stated Destination Preferences and Actual Travel. Journal of Vacation Marketing, 12, 319-328. http://dx.doi.org/10.1177/1356766706067604

[9] Gonzalez, C. (2005) Satisfaction du consommateur suite à la visite du catalogue électronique: Impact de la lisibilité perçue et de la stimulation perçue. Revue Française de Marketing, 205, 91-110. 
Scientific Research Publishing (SCIRP) is one of the largest Open Access journal publishers. It is currently publishing more than 200 open access, online, peer-reviewed journals covering a wide range of academic disciplines. SCIRP serves the worldwide academic communities and contributes to the progress and application of science with its publication.

Other selected journals from SCIRP are listed as below. Submit your manuscript to us via either submit@scirp.org or Online Submission Portal.
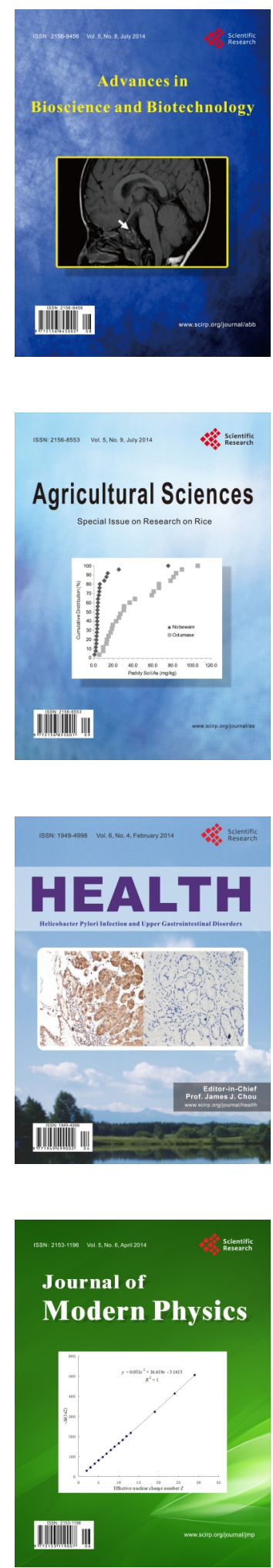
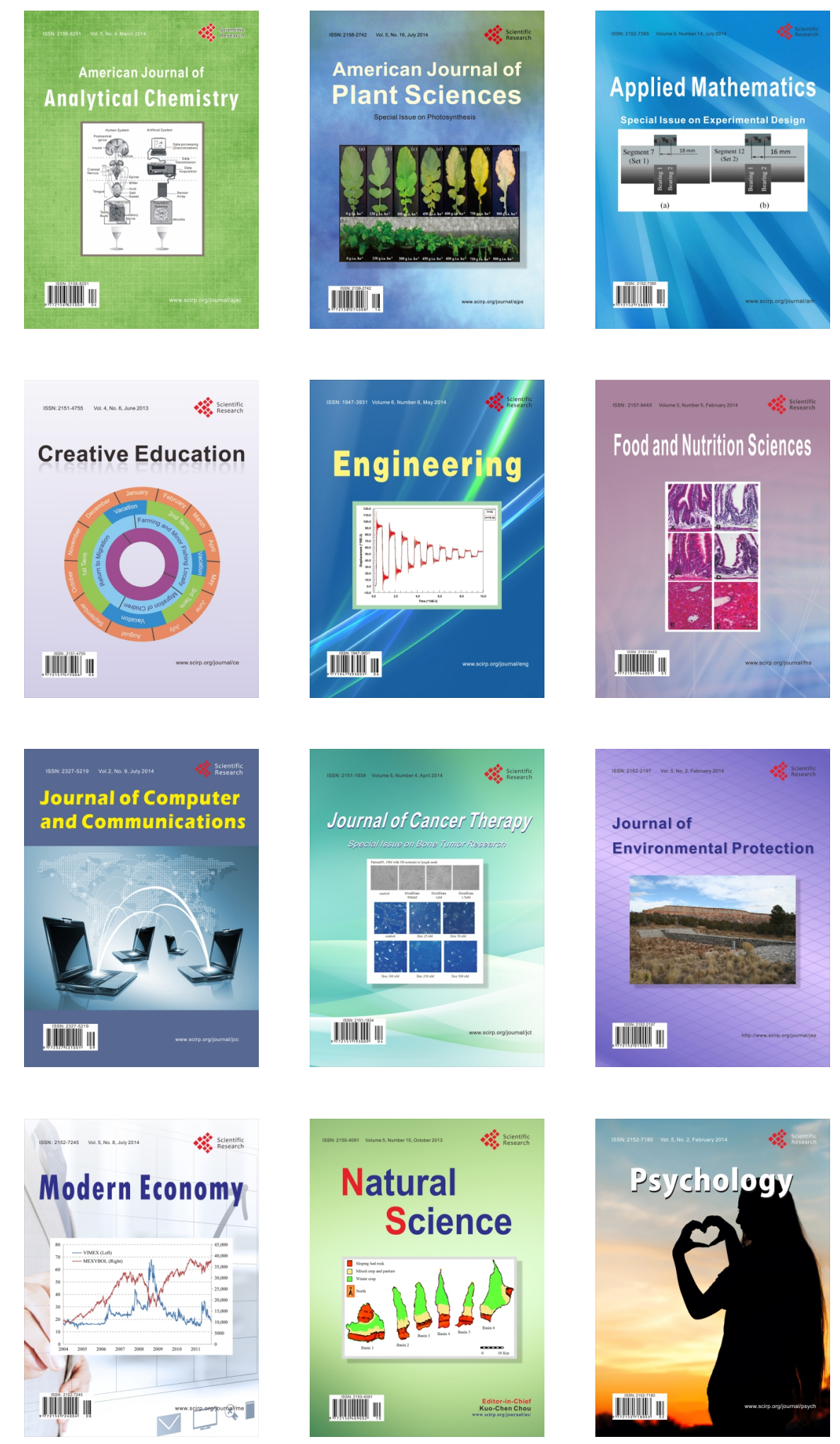